\title{
Comparison between the efficacies of Risperidone with Haloperidol in the treatment of attention-deficit hyperactivity disorder (ADHD) among preschoolers: a randomized double-blind clinical trial
}

\author{
Forough Riahi ${ }^{1}$, Ashraf Tashakori ${ }^{1}$, Leila Abdi ${ }^{2}$
}

${ }^{1}$ Child and Adolescent Psychiatrist, Associate Professor, Psychiatric Ward of Golestan Hospital, Jundishapur University of Medical Sciences, Ahvaz, Iran

${ }^{2}$ Resident of Psychiatry, Psychiatric Ward of Golestan Hospital, Jundishapur University of Medical Sciences, Ahvaz, Iran

\section{Type of article: Original}

\begin{abstract}
Background: Attention-deficit hyperactivity disorder (ADHD) is a common psychiatric disease with a worldwide pooled prevalence of $5.29 \%$.

Objective: To compare the efficacy of Risperidone with Haloperidol in the treatment of attention-deficit hyperactivity disorder (ADHD) among 3- to 6-year-old children.

Methods: In a 6-week double-blind clinical trial, the efficacy of Risperidone 0.5-2 $\mathrm{mg}$ with a dose of maximum Haloperidol $0.075 \mathrm{mg} / \mathrm{kg}$ was assessed in 39 children aged 3-6 years. This study was conducted at the Golestan Psychiatric Clinic (Ahvaz, Iran). Measurement tools included the Conners' Parent Rating Scale (CPRS-48), Children's Global Assessment Scale (CGAS), and the Attention Deficit Hyperactivity Disorder Rating Scale (ADHD-RS). Data were analyzed using the Wilcoxon, Mann-Whitney, and Fisher's exact tests in the SPSS 19.

Results: During the 6 weeks, the decline in points was seen in Conner's rating scale and in ADHD-RS score in Risperidone and Haloperidol groups $(\mathrm{p}<0.001)$. On the CGAS scale, an increase of performance in both groups for six weeks was statistically significant $(\mathrm{p}<0.001)$. In the scales of ADHD-RS and CPRS-48, no statistically significant difference was observed between the two treatment groups; i.e., in terms of reducing the rate during weeks of two, four, and six ( $\mathrm{p}>0.05)$.

Conclusions: Haloperidol and Risperidone possibly can be an acceptable treatment choice in the ADHD treatment of 3- to 6-year-old children.

Trial registration: The trial was registered at the Iranian Registry of Clinical Trials (http://www.irct.ir) with the Irct ID: IRCT2015082623766N1.

Funding: This work was financially supported by grant (ref. no.: U-93130) from the vice chancellor for Research Affairs of Ahvaz Jundishapur University of Medical Sciences.

Keywords: Attention-deficit hyperactivity disorder, Efficacy, Haloperidol, Risperidone
\end{abstract}

\section{Introduction}

Attention-deficit hyperactivity disorder (ADHD) is a common psychiatric disease with a worldwide pooled prevalence of $5.29 \%$ (1). Two population-based epidemiological studies in Iran found that $15 \%$ of preschoolers had ADHD symptoms $(2,3)$. According to the research conducted by the American Academy of Child and Adolescents, ADHD in preschool children is a relatively stable diagnosis; thus, it needs long-term or repeated episodes of behavioral and pharmacological therapies (4). Drug therapy is not prohibited for preschoolers, but it should only be used for moderate to severe impairment in children because a lot of these children only have improved with behavioral interventions and parental education (5). About half of preschoolers with a diagnosis of ADHD would be treated, and one of these four children is just treated with drug therapy (6). Methylphenidate is the most common drug used in the treatment of children diagnosed with ADHD; although for children less than 6 years old, the use of

\section{Corresponding author:}

Dr. Leila Abdi, Psychiatric Ward of Golestan Hospital, Jundishapur University of Medical Sciences, Ahvaz, Iran Tel: +98.9166126990, Email: leilaabdi1635@gmail.com

Received: February 12, 2016, Accepted: April 23, 2016, Published: September 2016

iThenticate screening: April 23, 2016, English editing: August 01, 2016, Quality control: August 06, 2016

(C) 2016 The Authors. This is an open access article under the terms of the Creative Commons Attribution-NonCommercialNoDerivs License, which permits use and distribution in any medium, provided the original work is properly cited, the use is non-commercial and no modifications or adaptations are made. 
this medication has not yet been approved by the Food and Drug Administration (FDA) (7). Only Dextroamphetamine and Adderall have been approved by the FDA for children aged 3 to 6 years; although in this age group, when the children are treated with stimulants, they will experience more side effects (8). For the treatment of ADHD, other pharmaceutical classes also have been tested $(9,10)$. In ADHD, there are impulsivity and loss of self-control resulting from aberrant dopamine dysfunction $(11,12)$. Given that children with ADHD have low tonic levels of dopamine and because the feedback system causes hyper bursts in them, this increases sensitivity to environmental stimuli and the attention deficit of the child $(13,14)$. Antipsychotics can increase tonic dopamine levels and reduce burst responses via negative feedback $(15,16)$. Therapeutic effects of antipsychotics are caused by their antagonistic effects on D2 receptors (17). The FDA has approved some antipsychotics for the treatment of severe emotional and behavioral disorders of children; however, the antipsychotics used for the purpose belong to both groups approved and unapproved (off label) by the FDA (18). It has been shown that atypical antipsychotics can treat the symptoms of ADHD (19). It has been especially shown that Risperidone can improve attention and hyperactivity in children with a diagnosis of ADHD (20). After the failure of non-antipsychotic treatment and psychotherapy, the FDA approved Haloperidol for hyperactive behaviors in children older than 3 years. While it seems that first-generation antipsychotic drugs have more side effects than the second-generation ones, there are not enough evidence and information for this (21); even now at least $90 \%$ of the antipsychotic drugs prescribed for children are second-generation drugs (22). According to studies, both drugs are among the off-label treatment of ADHD; thus, due to the lack of study to compare Haloperidol and Risperidone in the treatment of ADHD among preschoolers, this study was conducted.

\section{Material and Methods}

\subsection{Research design and participants}

This study was a double-blind clinical trial, which was conducted from March 20, 2014, to July 23, 2015. Out of 57 ADHD children aged 3 to 6 years old referred to the Golestan Psychiatric Clinic in Ahvaz (Iran) during six months, 46 children met the inclusion criteria. Nine subjects were excluded from the study; seven of these children were not scheduled for a next visit. Researchers excluded two children from the study because of medicinal complications. Ultimately, 39 children (18 children in the Haloperidol group and 19 persons in Risperidone group) completed the project. According to the DSM-IV TR criteria and interviews of the children by adolescence psychiatrists, ADHD was confirmed in these children.

\subsection{Inclusion and exclusion criteria}

Inclusion criteria were children ages 3 to 6 old years with a diagnosis of ADHD, the parents' written consent, at least 20 scores based on an ADHD-Raring scale, and $<50$ based on CGAS. Exclusion criteria were any medical conditions and comorbid psychiatric disorders, including mood disorders, anxiety disorders, pervasive developmental disorder, tic, and mental retardation and if the patients had been receiving any medicinal or nonmedicinal treatments two weeks before the study. Due to the unwillingness and inability in taking tablets, these children were excluded from the study and were examined at baseline and subsequent visits.

\subsection{Efficacy measures}

The instruments used in this research were:

1) The Conners' Parent Rating Scale-48 (CPRS-48) was used for all participants. This form includes 48 questions and evaluates the symptoms; in addition, using a 4-point Likert scale (at all, to some extent, high and very high), scoring of questions is carried out (23). This scale also has been standardized in Iran (24).

2) The Attention Deficit Hyperactivity Disorder Rating scale (ADHD-RS) is a questionnaire with 14 questions. Subscales of attention deficit, hyperactivity, and impulsivity can be extracted from it. It is on the basis of DSM IV IR and measures and scores the disorder symptoms from 0 (lack of signs) to 3 (severe). In most studies, a validity coefficient of more than 90 has been reported for it (25).

3) The Children's Global Assessment Scale (CGAS), designed for diagnosing the performance of children and adolescents less than 20 years old, has a moderate inter-rater reliability and is graded in the form of numbered intervals of 10 and from 1 to 100 (26).

4) The medicinal side-effect questionnaire was set up on the basis of a reference (27) and includes motor, vegetative, sexual, gastrointestinal, neurological, etc. side effects. It can be described qualitatively (never, sometimes continuously). 


\subsection{Procedure}

First of all, this study was approved by the ethics committee of Ahvaz Jundishapur University of Medical Sciences (ajums.REC.13930305). Children participating in a double-blind clinical trial were selected randomly and then blocked and treated with Risperidone or Haloperidol for six weeks. Drugs were placed in envelopes and labeled group one and group two; for this reason, the evaluator, the patient, and his or her family were not aware of the type of prescribed drugs. The starting dose of Risperidone was $0.25 \mathrm{mg}$ per day ( $1 \mathrm{mg}$ tablets); then during the first two weeks of treatment, a $0.25 \mathrm{mg}$ dose of drug was given twice a day; then gradually, based on the therapeutic response and tolerance of side effects of the drug, we increased the dose. The final maximum dose for Risperidone was $2 \mathrm{mg}$ ( $1 \mathrm{mg}$ twice a day). $0.5 \mathrm{mg}$ of Haloperidol tablet was started in two divided doses. During the first two weeks of treatment, it was increased to $0.5 \mathrm{mg}$ twice daily; in addition, based on clinical response and medication side effect tolerability, the dose was increased; the final maximum dose of Haloperidol was $0.075 \mathrm{mg} / \mathrm{kg}$ (28). In the event of any extrapyramidal side effects during treatment, 5 to $7.5 \mathrm{mg}$ of diphenhydramine syrup was given every six hours; and, if necessary, it was increased maximum up to $37.5 \mathrm{mg}$ per day. During weeks $0,2,4$, and 6 , patients were visited by a child psychiatrist and a psychiatric resident; then questionnaires of ADHD-RS, and CPRS-48 were completed in weeks $0,2,4$, and 6; furthermore, a medicinal side-effects questionnaire was completed in weeks 2, 4, and 6 and CGAS in weeks 0 and 6 . It should be noted that, in all duration of the treatment and an evaluation, to avoid incorrect information, the more-aware parent was selected for the evaluation; also up to the end of the treatment, the same parent continued the evaluation of the questionnaire. Before the start of the study, the study objectives and side-effects were explained to the parents. After signing the written consent forms by parents, children were included in the study.

\subsection{Statistical analysis}

Data were analyzed using SPSS version 19; a summary of statistical data was reported in the form of mean and standard deviation. To determine the relationship between qualitative variables, Fisher's exact test was used; in addition, to compare the average results, the Wilcoxon and Mann-Whitney test was used, and a p-value less than 0.05 was considered as significant.

\section{Results}

Of the 39 children who had inclusion criteria, 20 patients were treated with Haloperidol and 19 were treated with Risperidone; in the second week of the study, due to severe extrapyramidal side effects, two boys from the Haloperidol group were excluded from the study. The two groups were matched in terms of age and gender; no statistically significant difference existed in terms of age $(\mathrm{p}=0.7)$ and gender $(\mathrm{p}=0.27)$ between the two groups. The average dose of Haloperidol and Risperidone was $0.95 \pm 0.1 \mathrm{mg}$ and $1.52 \pm 0.2 \mathrm{mg}$, respectively. In both groups, compared with the average rating of CPRS, a statistically significant difference in score decline was observed between the baseline and sixth week of the treatment $(p<0.001)$; in addition, a statistically significant difference in the average ADHD-RS total score reduction was observed within Risperidone $(\mathrm{p}=0.003)$ and Haloperidol $(\mathrm{p}<0.001)$ groups after six weeks. Table 1 shows all of these features at the start and end of the study. On the ADHD-RS scale, no statistically significant difference was seen in the score decline rate in the second $(\mathrm{p}=0.06)$, fourth $(\mathrm{p}=0.1)$, and sixth ( $\mathrm{p}=0.3$ ) weeks between the two groups.

Table 1. Characteristics of the patients in Risperidone and Placebo groups at the baseline and end line

\begin{tabular}{|c|c|c|c|c|}
\hline \multicolumn{2}{|l|}{ Variable } & Haloperidol group $(n=18)$ & Risperidone group $(n=19)$ & $\mathrm{p}$-value \\
\hline \multirow{2}{*}{ Gender } & Male & 12 & 16 & \multirow[t]{2}{*}{0.27} \\
\hline & Female & 6 & 3 & \\
\hline \multicolumn{2}{|l|}{ Age $($ year $\pm S D)$} & $4.2 \pm 1$ & $4.1 \pm 0.9$ & 0.70 \\
\hline & & $($ Mean \pm SD) & $($ Mean \pm SD) & \\
\hline \multirow{2}{*}{ Conners } & Baseline & $112.5 \pm 15.4$ & $112.4 \pm 16.8$ & 0.98 \\
\hline & Endline & $88.3 \pm 17.4$ & $88.2 \pm 9.6$ & 0.98 \\
\hline \multirow[t]{2}{*}{ Total ADHD } & Baseline & $33 \pm 8.7$ & $33.9 \pm 8.6$ & 0.8 \\
\hline & Endline & $21.5 \pm 8.8$ & $22 \pm 6.9$ & 0.8 \\
\hline \multirow[t]{2}{*}{ Hyperactivity } & Baseline & $9.5 \pm 3.1$ & $9.8 \pm 2.7$ & 0.86 \\
\hline & Endline & $6.1 \pm 2.9$ & $6.3 \pm 2.7$ & 0.79 \\
\hline \multirow[t]{2}{*}{ Attention-deficit } & Baseline & $14.6 \pm 3.5$ & $14.7 \pm 3.7$ & 0.75 \\
\hline & Endline & $9.8 \pm 4.3$ & $9.3 \pm 3.5$ & 0.73 \\
\hline \multirow[t]{2}{*}{ Impulsivity } & Baseline & $8.7 \pm 2.7$ & $9.4 \pm 3.1$ & 0.36 \\
\hline & Endline & $5.6 \pm 2.5$ & $6.5 \pm 2.3$ & 0.26 \\
\hline
\end{tabular}


Despite a lack of a statistically significant difference between the two groups, score decline in the Risperidone group was more than the Haloperidol group (Figures 1-4). Regarding the findings of CPRS-48, no significant difference existed in the reduction of symptoms in the second $(\mathrm{p}=0.5)$, fourth $(\mathrm{p}=0.6)$, and sixth $(\mathrm{p}=0.8)$ weeks (Figure 5). While the difference between groups was not statistically significant, the rate of score decline in the Risperidone group was more than in the Haloperidol group. These results are shown in Table 2.

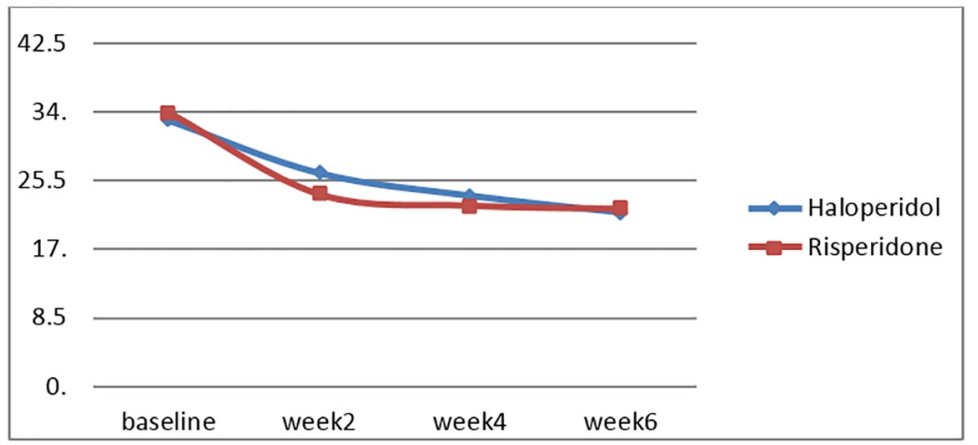

Figure 1. Comparison between the two groups using ADHD rating scale

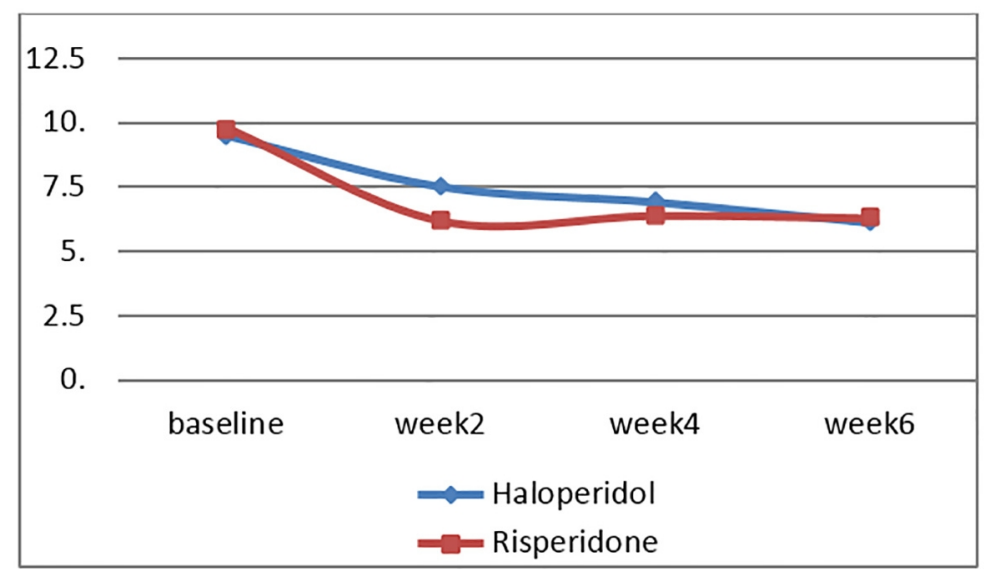

Figure 2. Comparison between the two groups using hyperactivity subscale

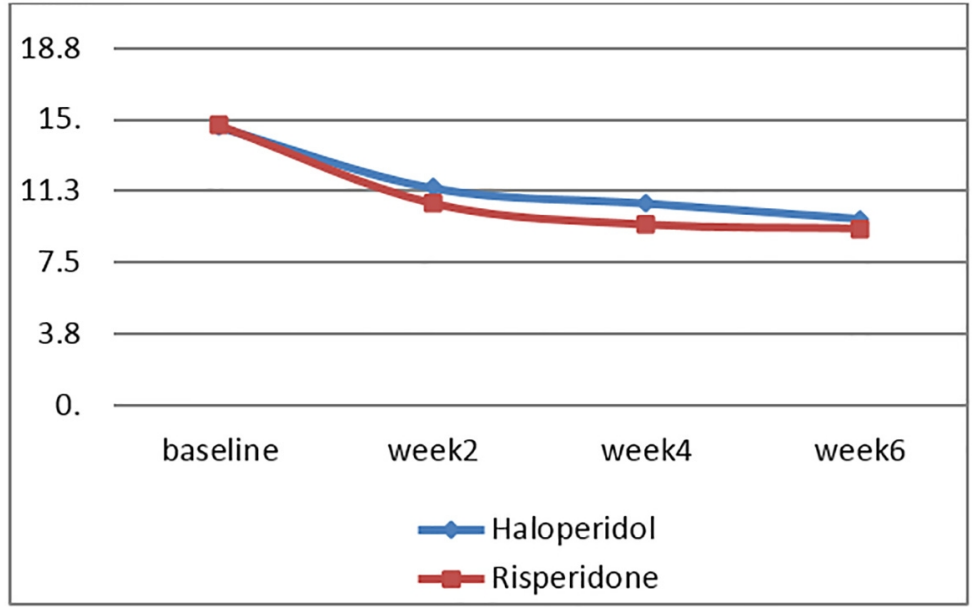

Figure 3. Comparison between the two groups using attention deficit subscale 


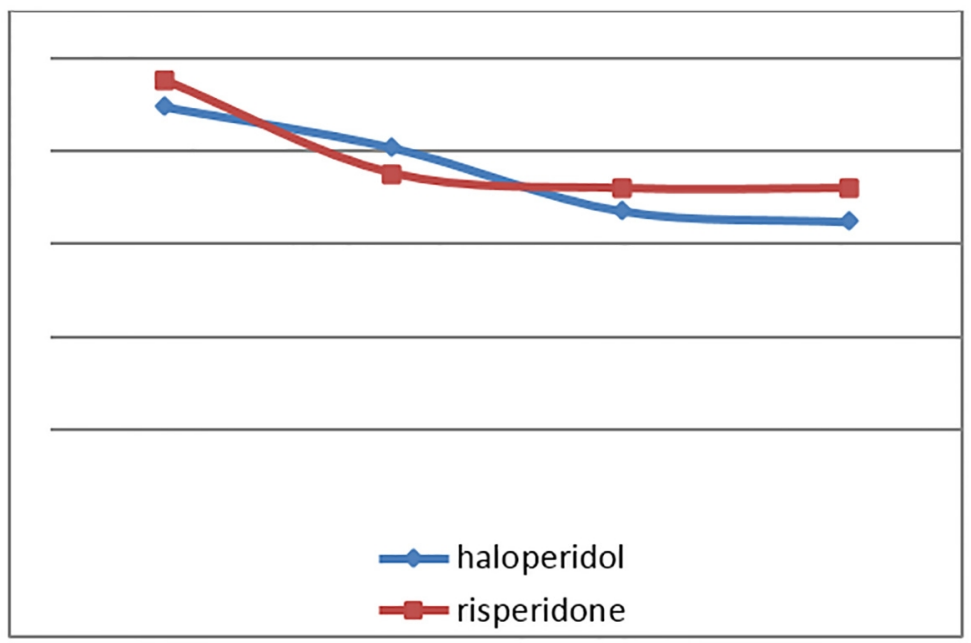

Figure 4. Comparison between the two groups using impulsivity subscale

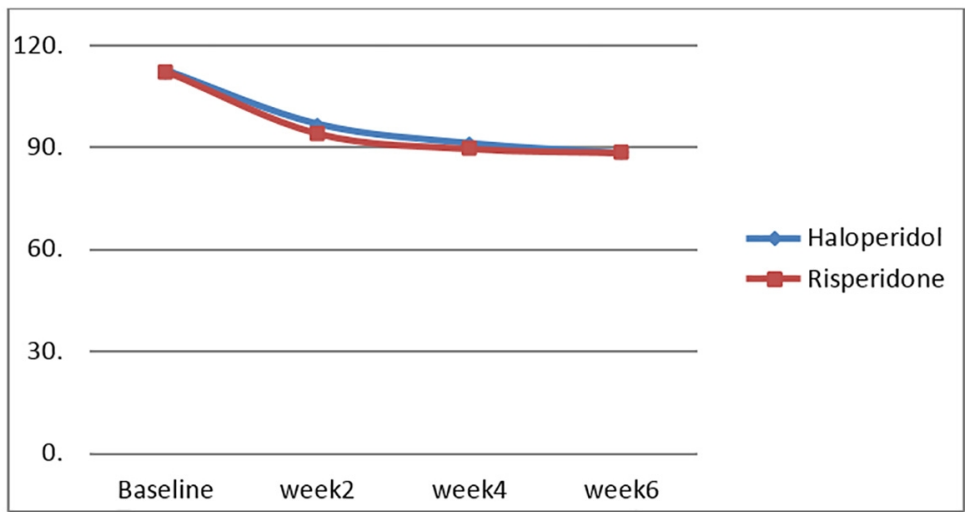

Figure 5. Comparison between the two groups using Conners' parent rating scale

Table 2. Comparison between the two groups in average reduction of measures in the second, fourth, and sixth weeks

\begin{tabular}{|l|l|l|l|}
\hline Variable & Haloperidol group (Mean \pm SD) & Risperidone group (Mean \pm SD) & $p$-value \\
\hline CPRS week 6 & $24.2 \pm 18.9$ & $24.2 \pm 16$ & 0.8 \\
\hline CPRS week 4 & $21.3 \pm 19.8$ & $22.9 \pm 16.4$ & 0.6 \\
\hline CPRS week 2 & $15.7 \pm 21$ & $18.4 \pm 12.8$ & 0.5 \\
\hline ADHD-RS week 6 & $11.5 \pm 8.3$ & $11.9 \pm 11.9$ & 0.3 \\
\hline ADHD-RS week 4 & $9.4 \pm 8.7$ & $11.5 \pm 11.6$ & 0.1 \\
\hline ADHD-RS week 2 & $6.5 \pm 7.8$ & $10 \pm 7.5$ & 0.06 \\
\hline Hyperactivity subscale week 6 & $3.4 \pm 2.5$ & $3.5 \pm 3.9$ & 0.5 \\
\hline Hyperactivity subscale week 4 & $2.6 \pm 2.6$ & $3.4 \pm 3.7$ & 0.2 \\
\hline Hyperactivity subscale week2 & $2 \pm 2.6$ & $3.5 \pm 2.8$ & 0.09 \\
\hline Attention-Deficit subscale week6 & $4.8 \pm 3.9$ & $5.5 \pm 5.4$ & 0.4 \\
\hline Attention-Deficit subscale week4 & $4 \pm 4$ & $5.2 \pm 4.9$ & 0.3 \\
\hline Attention-Deficit subscale week2 & $3.2 \pm 3.1$ & $4.1 \pm 3.8$ & 0.3 \\
\hline Impulsivity subscale week 6 & $3.2 \pm 3.1$ & $2.9 \pm 3.7$ & 0.9 \\
\hline Impulsivity subscale week 4 & $2.8 \pm 3.4$ & $2.9 \pm 3.7$ & 0.7 \\
\hline Impulsivity subscale week 2 & $1.2 \pm 2.8$ & $2.4 \pm 2.5$ & 0.08 \\
\hline
\end{tabular}

Regarding the findings of CGAS, in the Haloperidol group, three children had a performance from 1 to 10,15 children had a performance from 11 to 20; in the Risperidone group, four children had a performance from 1 to 10 , and 15 children had a performance from 11 to 20. Finally, they all yielded to a performance of 40-50 at the end of 
the sixth week. In both groups, an increase in the performance between zero and six weeks was statistically significant $(\mathrm{p}<0.001)$. It should be noted that no specific pathological point was seen in any of the children, except for the two aforementioned extrapyramidal side effects. According to Table 2, out of Haloperidol group, two children suffered a combination of severe extrapyramidal side effects. They did not reply to diphenhydramine and were excluded from the study due to the intensity of the side effects; thus, they underwent other standard treatments by researchers. In both groups, the pharmaceutical side effects such as increased appetite and constipation and morning drowsiness were mild effects. By reducing of doses, all these effects were removed; eventually, except for extrapyramidal side effects, all other side effects were tolerated with the therapeutic measures, and all these children continued to the end of the plan (Table 3 ).

Table 3. Comparison of adverse events between Risperidone and Haloperidol

\begin{tabular}{|l|l|l|}
\hline Variable & Haloperidol; $n(\%)$ & Risperidone; $n(\%)$ \\
\hline Increased appetite & $2(10)$ & $3(15)$ \\
\hline Loss of appetite & $0(0)$ & $0(0)$ \\
\hline Morning somnolence & $1(5)$ & $2(10.5)$ \\
\hline Tics & $0(0)$ & $0(0)$ \\
\hline Tremor & $0(0)$ & $0(0)$ \\
\hline Rigidity & $1(5)$ & $0(0)$ \\
\hline Restlessness & $2(10)$ & $0(0)$ \\
\hline Dry mouth & $1(5)$ & $0(0)$ \\
\hline Blurred vision & $0(0)$ & $0(0)$ \\
\hline Irritability & $0(0)$ & $0(0)$ \\
\hline Nausea & $0(0)$ & $0(0)$ \\
\hline Diarrhea & $0(0)$ & $0(0)$ \\
\hline Nucturnal eruresis & $1(5)$ & $2(10.5)$ \\
\hline Diurnal enuresis & $0(0)$ & $0(0)$ \\
\hline Sexual problems & $0(0)$ & $0(0)$ \\
\hline
\end{tabular}

\section{Discussion}

The clinical double-blind trial was conducted to investigate the efficacy of Haloperidol compared with Risperidone in the 3- to 6-year-old children with ADHD. Finally, it was found that the two drugs were significantly effective in reducing the symptoms of this disorder in the study; however, their efficacies did not show a difference in reducing the symptoms. These results are consistent with Biderman et al.'s study in 2008 (20). In that study, modest improvement of the efficacy of Risperidone was seen in 4- to 15-year-old children with ADHD and bipolar diagnosis. This may be due to bipolar disorder comorbidities that caused lesser efficacy of Risperidone than in our study. It is also consistent with the results of Malone et al. in 2001 (29). In that study, with a similar dose range of our study, Haloperidol had been effective in the treatment of autistic children. These findings were inconsistent with the study conducted by Gancer et al. in 2008 (30). In that study, with a dose range similar to our study, Risperidone's efficacy in autistic disorder was compared with Haloperidol, among 8- to 18-year-old children. In that study, Risperidone was more effective than Haloperidol; it also was better tolerated over the long term. The difference may be due to the increased sensitivity of autistic children to side effects of Haloperidol. A longer duration of 24 months of the study compared with our study could be another reason for the difference in results. The findings were consistent with a study by Masi et al. in 2003 (31). In that study, preschool children diagnosed with PDD were investigated for 3 years; however, they received a smaller dose of Risperidone compared with those in our study $(0.55 \pm 0.2 \mathrm{mg})$; finally, a considerable improvement was seen in the CPRS and CGAS. In this study, because the PDD patients were more sensitive to the medicinal side effect, a low dose of Risperidone was prescribed; it was observed that it is effective in the long run. In the CGAS scale in both groups at the end of the sixth week, compared with the baseline, an increase in function was observed, which is statistically significant; this suggests that both of these medications, with a significant role in the performance of children, improve ADHD symptoms; thus, this result is consistent with Masi et al.'s study in 2003 (31). In that study, an increase in CGAS was observed in treatment with Risperidone in children with PDD. In terms of the adverse effects, both drugs were generally well-tolerated, and only two children were excluded due to severe extrapyramidal side effects. This result is justified according to the high extrapyramidal side effects of Haloperidol than of Risperidone. Thus, this result is consistent with a review study by Brock et al. in 2007 (23). Because most side effects of antipsychotic drugs happen in the first weeks of treatment and increased tolerance to medicinal side effects with the progress of the treatment; it 
can be said that, during the study, both drugs have had the acceptable side effects, although a longer time is needed for performing a better study of metabolic side effects and weight effect of, especially Risperidone. Since the end of the study, all children in both groups had significant improvement, and their performance was improved at an acceptable level; thus, it can be said that Risperidone and Haloperidol in preschool children, especially in regards to the side effects of stimulants, are acceptable choices. Some limitations of this study included a small sample size and short duration of the study.

\section{Conclusions}

This study is the first study that compared Risperidone and Haloperidol in the treatment of ADHD in preschool children. Our findings showed Risperidone and Haloperidol probably can be applied as effective and well-tolerated treatments in 3- to 6-year-old children with a diagnosis of ADHD with moderate to severe dysfunction. However, a better generalization of the results necessitates further studies in this field with a more sample size and in a longer duration; furthermore, we recommend studies of efficacy and side effects of each of these two drugs in this age group compared with stimulants

\section{Acknowledgments:}

The authors also thank cooperative parents and the staffs at the psychiatric clinic of Golestan Hospital and the Golestan Clinical Research Development Unit.

\section{Trial registration:}

The trial was registered at the Iranian Registry of Clinical Trials (http:/www.irct.ir) with the Irct ID: IRCT2015082623766N1.

\section{Funding:}

This work was financially supported by grant (ref. no.: U-93130) from the vice chancellor for Research Affairs of Ahvaz Jundishapur University of Medical Sciences.

\section{Conflict of Interest:}

There is no conflict of interest to be declared.

\section{Authors' contributions:}

All authors contributed to this project and article equally. All authors read and approved the final manuscript.

\section{References:}

1) Polanczyk G, de Lima MS, Horta BL, Biederman J, Rohde LA. The worldwide prevalence of ADHD: a systematic review and metaregression analysis. Am J Psychiatry. 2007; 164(6): 942-8. doi: 10.1176/ajp.2007.164.6.942. PMID: 17541055.

2) Ardalan G, Farhoud DD, Shah Mohammadi D. Hyperactivity, attention and concentration deficit in preschool children. Iranian Journal of Pediatrics. 2002; 12(4): 53-6.

3) Tashakori A, Afkandeh R. Prevalence of ADHD Symptoms amonge Male Preschoolers Based on Different Informants in Ahvas City of Iran. ISRN pediatrics. 2011; 2011: 709653. doi: 10.5402/2011/709653. PMID: 22389785, PMCID: PMC3263576.

4) Ferguson JH. National Institutes of Health Consensus Development Conference Statement: Diagnosis and treatment of attention-deficit/hyperactivity disorder (ADHD). Journal of the American Academy of Child \& Adolescent Psychiatry. 2000; 39(2): 182-93. doi: 10.1097/00004583-200002000-00018.

5) Clinical practice guideline: diagnosis and evaluation of the child with attention-deficit/hyperactivity disorder. Pediatrics. 2000; 105(5): 1158-70. doi: 10.1542/peds.105.5.1158. PMID: 10836893.

6) Visser SN, Bitsko RH, Danielson ML, Ghandour RM, Blumberg SJ, Schieve LA, et al. Treatment of Attention Deficit/Hyperactivity Disorder among Children with Special Health Care Needs. J Pediatr. 2015; 166(6): 1423-30. doi: 10.1016/j.jpeds.2015.02.018. PMID: 25841538, PMCID: PMC4469986.

7) Wigal T, Greenhill L, Chuang S, McGough J, Vitiello B, Skrobala A, et al. Safety and tolerability of methylphenidate in preschool children with ADHD. J Am Acad Child Adolesc Psychiatry. 2006; 45(11): 1294-303. doi: 10.1097/01.chi.0000235082.63156.27. PMID: 17028508.

8) Rosenberg D, Gershon S. Pharmacotherapy for child and adolescent psychiatric disorders: CRC Press; 2002. 
9) Riahi F, Tehrani-Doost M, Shahrivar Z, Alaghband-Rad J. Efficacy of reboxetine in adults with attention deficit/hyperactivity disorder: A randomized, placebo - controlled clinical trial. Hum Psychopharmacol. 2010; 25 (7 - 8): 570-6. doi: 10.1002/hup.1158. PMID: 21312292.

10) Riahi F, Tashakori A, Izadi-Mazidi S, Salehi-Veysi M. Effectiveness of Reboxetine in Treatment of Outpatient Children and Adolescents with Attention Deficit-Hyperactivity Disorder with Comorbid Anxiety Disorders. Iran J Psychiatry. 2013; 8(4): 195. PMID: 25628714 , PMCID: PMC4281655.

11) Winstanley CA, Eagle DM, Robbins TW. Behavioral models of impulsivity in relation to ADHD: translation between clinical and preclinical studies. Clin Psychol Rev. 2006; 26(4): 379-95. doi: 10.1016/j.cpr.2006.01.001. PMID: 16504359, PMCID: PMC1892795.

12) O'Sullivan SS, Evans AH, Lees AJ. Dopamine dysregulation syndrome: an overview of its epidemiology, mechanisms and management. CNS Drugs. 2009; 23(2): 157-70. doi: 10.2165/00023210-20092302000005. PMID: 19173374.

13) Goto Y, Otani S, Grace AA. The Yin and Yang of dopamine release: a new perspective. Neuropharmacology. 2007; 53(5): 583-7. doi: 10.1016/j.neuropharm.2007.07.007. PMID: 17709119, PMCID: PMC2078202.

14) Sikstrom S, Soderlund G. Stimulus-dependent dopamine release in attention-deficit/hyperactivity disorder. Psychol Rev. 2007; 114(4): 1047-75. doi: 10.1037/0033-295X.114.4.1047. PMID: 17907872.

15) Braun A, Laruelle M, Mouradian M. Interactions between D1 and D2 dopamine receptor family agonists and antagonists: the effects of chronic exposure on behavior and receptor binding in rats and their clinical implications. Journal of neural transmission. 1997; 104(4-5): 341-62. doi: 10.1007/BF01277656. PMID: 9295170.

16) Samaha AN, Seeman P, Stewart J, Rajabi H, Kapur S. Breakthrough dopamine supersensitivity during ongoing antipsychotic treatment leads to treatment failure over time. J Neurosci. 2007; 27(11): 2979-86. doi: 10.1523/JNEUROSCI.5416-06.2007. PMID: 17360921.

17) Owen R, Owen F, Poulter M, Crow TJ. Dopamine D 2 receptors in substantia nigra in schizophrenia. Brain research. 1984; 299(1): 152-4. doi: 10.1016/0006-8993(84)90798-4.

18) Pathak P, West D, Martin BC, Helm ME, Henderson C. Evidence-based use of second-generation antipsychotics in a state Medicaid pediatric population, 2001-2005. Psychiatr Serv. 2010; 61(2): 123-9. doi: 10.1176/ps.2010.61.2.123. PMID: 20123816.

19) Cheng-Shannon J, McGough JJ, Pataki C, McCracken JT. Second-generation antipsychotic medications in children and adolescents. J Child Adolesc Psychopharmacol. 2004; 14(3): 372-94. doi: 10.1089/cap.2004.14.372. PMID: 15650494.

20) Biederman J, Hammerness P, Doyle R, Joshi G, Aleardi M, Mick E. Risperidone treatment for ADHD in children and adolescents with bipolar disorder. Neuropsychiatr Dis Treat. 2008; 4(1): 203-7. doi: 10.2147/NDT.S1992. PMID: 18728799, PMCID: PMC2515893.

21) Seida JC, Schouten JR, Mousavi SS, Hamm M, Beaith A, Vandermeer B, et al. First-and second-generation antipsychotics for children and young adults. 2012.

22) Maglione M, Maher AR, Hu J, Wang Z, Shanman R, Shekelle PG, et al. Off-label use of atypical antipsychotics: an update. 2011. PMID: 22132426.

23) Brock SE, Clinton A. Diagnosis of attention-deficit/hyperactivity disorder (AD/HD) in childhood: A review of the literature. The California School Psychologist. 2007; 12(1): 73-91. doi: 10.1007/BF03340933.

24) Shayan A ST, Beaming L, yousefi F. Normalization factor analysis and reliability of the short form of special conners parent rating scale for children in Shiraz city. J of psychological studies. 2007; 3(3): 97120.

25) Kuperman S, Perry PJ, Gaffney GR, Lund BC, Bever-Stille KA, Arndt S, et al. Bupropion SR vs, methylphenidate vs, placebo for attention deficit hyperactivity disorder in adults. Ann Clin Psychiatry. 2001; 13(3): 129-34. doi: 10.3109/10401230109148958. PMID: 11791949.

26) Lundh A, Kowalski J, Sundberg CJ, Gumpert C, Landén M. Children's Global Assessment Scale (CGAS) in a naturalistic clinical setting: Inter-rater reliability and comparison with expert ratings. Psychiatry Res. 2010; 177(1): 206-10. doi: 10.1016/j.psychres.2010.02.006. PMID: 20334931.

27) Kutcher SP, Lauria-Horner BA, MacLaren CM, Bujas-Bobanovic M. Practical child and adolescent psychopharmacology: Cambridge University Press; 2002. doi: 10.1017/CBO9780511543920.

28) Pliszka SR, Greenhill LL, Crismon ML, Sedillo A, Carlson C, Conners CK, et al. The Texas Children's Medication Algorithm Project: Report of the Texas Consensus Conference Panel on Medication Treatment 
of Childhood Attention-Deficit/Hyperactivity Disorder, Part I. Journal of the American Academy of Child \& Adolescent Psychiatry. 2000; 39(7): 908-19. doi: 10.1097/00004583-200007000-00021.

29) Malone RP, Cater J, Sheikh RM, Choudhury MS, Delaney MA. Olanzapine versus haloperidol in children with autistic disorder: an open pilot study. J Am Acad Child Adolesc Psychiatry. 2001; 40(8): 887-94. doi: 10.1097/00004583-200108000-00009. PMID: 11501687.

30) Gencer O, Emiroglu FN, Miral S, Baykara B, Baykara A, Dirik E. Comparison of long-term efficacy and safety of risperidone and haloperidol in children and adolescents with autistic disorder. Eur Child Adolesc Psychiatry. 2008; 17(4): 217-25. doi: 10.1007/s00787-007-0656-6. PMID: 18026891.

31) Masi G, Cosenza A, Mucci M, Brovedani P. A 3-year naturalistic study of 53 preschool children with pervasive developmental disorders treated with risperidone. J Clin Psychiatry. 2003; 64(9): 1039-47. doi: 10.4088/JCP.v64n0909. PMID: 14628979. 